\title{
Case management for people with dementia and its translations: a discussion paper
}

\section{Abstract}

Case management is generally seen as a way to provide efficient, cost-saving personcentred care for people with dementia by connecting together fragmented services, but the available evidence in favour of its merits is often considered inconclusive, unclear and sketchy. This discussion paper investigates the evidence of the benefit of case management for people with dementia, and explores the complexity of the concept and the experiences of its implementation. It offers a comprehensive framework for conceptualising various types of case management and asks the question: who can be a case manager? Building on examples from three European countries it addresses the problem of the expansion and adoption of the case management method. It compares the conventional model of diffusion of innovation with the ideas of interessement and co-constitution and envisions a successful model of case management as a fluid technology that is both friendly and flexible, allowing it to adapt to different settings and systems.

\section{Keywords}

case management, dementia, fluid technology, interessement, translation of case management 


\section{Introduction}

In Europe people with dementia syndrome and their carers all too often encounter services that are limited in resources, poorly coordinated, variable in quality and quantity, protocoldriven, inequitable, sometimes stigmatising and only weakly tailored to individual and family needs (Furnish, 2002; Leichsenring, Billings, \& Nies, 2013; Backhouse et al., 2015). Poor co-ordination appears, for example, as difficulties in information sharing between agencies or in practitioners referring ('signposting') the person with dementia and their carers to other agencies rather than adopting a problem-solving approach to assist them (Gray, 2012). Protocols and 'care pathways' can improve care quality, but can also result in mechanistic approaches to care (Penrod et al., 2007; McLean, 2007). For lack of other resources, family members may have no choice but to become 'care co-ordinators' themselves in order to keep the person with dementia's world together (Eggers, Norberg, \& Ekman, 2005). They encounter the failings of existing health and social care systems, in which access to appropriate medication may be reduced for those living in deprived areas (Cooper et al., 2016) whilst stigmatisation can lead to a loss of 'voice' for the person with dementia (Batsch, \& Mittelman, 2012).

These negative features appear common across Europe, where there is a need to develop new (or reconfigure existing) services for people with dementia and their families so that they experience a smoother journey along the illness trajectory and receive services that are more person-centred, effective and efficient (Warner, \& Furnish, 2002).

Because dementia affects an individual's global functioning, the needs of the person with dementia syndrome are often long-term and cumulative, requiring support from a complex matrix of networks and services at different points on the disease trajectory, as well as from 
family caregivers (Khanassov, Vedel, \& Pluye, 2014a; 2014b). The disease process develops insidiously, emerges through the personality of the individual, is easy to misattribute to ageing, is often feared and avoided by the individual and their family, and is too often recognised at a late stage, or in a crisis.

There are barriers to the recognition of and response to dementia at the level of the person affected and their family, the primary care doctor, and the wider health care system, including specialist hospital care and even within long-term residential care. Given these multiple barriers in primary and secondary care, it is easy to understand why providing timely, responsive, well-co-ordinated and person-centred clinical and social care is so difficult (Koch, \& lliffe, 2010).

The clinical picture is made complex by comorbidities. The widespread nature of 'diagnostic overshadowing' in people with mental illness is evident with dementia syndrome; the dementia obscures other potentially tractable disabilities, which receive unnecessarily delayed attention (Jones, Howard, \& Thornicroft, 2008; Connolly et al., 2013). This overshadowing may combine with low levels of knowledge about age-related disabilities and diseases in older people amongst the main carers of people with dementia, whether family members or staff in residential and nursing homes.

\section{Modelling case management approaches}

Although case management began as a clinical tool in the USA (Kanter, 1989), it has evolved into a way of working that is not restricted to clinicians or clinical activities alone. Case management approaches that start with a comprehensive assessment of needs shared between patients, caregivers and professionals show promise as a way to improve 
the quality of life of people with dementia and of their families, reduce health expenditure on inappropriate hospital admissions, and produce societal gains.

The Case Management Society of the United Kingdom defines case management as: "a collaborative process which: assesses, plans, implements, co-ordinates, monitors and evaluates the options and services required to meet an individual's health, social care, educational and employment needs, using communication and available resources to promote quality cost effective outcomes" (Case Management Society UK, 2010). Thus defined, case management has become an attractive policy for chronic disease management in England (Department of Health, 2004).

In the field of disability studies, where the emphasis is put on person-centred approaches, case management is described as: "a process of care planning and coordination of the services and resources used by people with disability and their families. Primary functions of case management include assessment, development of a care plan, securing access to services, and monitoring to ensure service timeliness, comprehensiveness, and quality over time" (Dill, 2006, pp. 228-229).

Considering the tasks of case management may help to clarify the definitions and operationalise case management in a more personalised way. According to Drennan and Goodman (2004, p. 527), the core elements of any case management activity at the individual patient level are:

- identification of individuals or carer-person dyads likely to benefit from case management,

- assessment of the individuals' problems and need for services,

- care planning of activities and services to address the agreed needs,

- co-ordination and referral to implement the care plan, and 
- regular review, monitoring and consequent adaptation of the care plan (components of continuity of care).

Apart of that, case managers can provide information, support and counselling based on the individual needs of the person with dementia and their informal caregiver (van Mierlo et al., 2014).

These core activities can be understood and implemented in various ways. For example, Walsh and Holton (2008), considering case management in general (not specifically about case management for people living with dementia), distinguish between three basic models: the 'broker' model, 'assertive community treatment' and 'intensive case management' with individual case managers. In the broker model, the most basic type of case management, case managers assess the needs of clients and connect them to appropriate resources in the community. As well as assessment, planning, linking and monitoring, they might engage in advocacy on behalf of the clients (Walsh, 2002), but they do not provide direct care to their clients and their approach is not built around helping relationships. Assertive community treatment (ACT), developed in the late 1970s for clients with serious mental illness, is provided by multidisciplinary teams, with the team members sharing the caseload. In this model, connecting clients to services is combined with providing direct care, with the emphasis on the latter, as well as on "direct, intensive, and aggressive outreach to clients" (Walsh, \& Holton, 2008, p. 142). The intensive case management model is similar to ACT, but according to this model, the care is delivered by one case manager rather than a multidisciplinary team. In comparison with case managers of the broker type, individual case managers spend much more time with clients.

Alternative typologies of case management have been formulated, depending on the author's viewpoint and on the nature of client population (see, for example, Dustin 2007). In the care for people with dementia, MacNeil Vroomen et al. $(2012 ; 2015)$ and van Mierlo et al. (2014), considering the Dutch experience, describe a 'linkage' model and a 'combined 
intensive case management/joint agency model'. Drennan and Goodman (2004), writing about nurse-led case management for older people with long-term conditions in the UK, adopt Beardshow's and Towell's (1990) distinction between the 'brokerage' and the 'key worker extension' models. According to this typology, case managers holding budgets to finance care packages for the client work according to a brokerage model, and case managers providing services themselves and co-ordinating other agencies' services implement a key worker extension model.

It is sometimes assumed that the brokerage and extensive key worker models could be located along an empowerment-professional control axis, with the brokerage model emphasising advocacy, empowerment and increasing client autonomy, whilst the key worker model is built around professional control over care planning, referrals and coordination of specialized services. However, a doubt remains if limiting services to "connecting [...] clients to appropriate resources in the community" (Walsh, \& Holton, 2008, p. 141) automatically leads to clients' empowerment and heightened autonomy. The assertive community treatment model, combining intensive direct care with the emphasis on the clients' informal support networks and her or his active role in planning and evaluating the care trajectory, represents a contrasting approach (Walsh, \& Holton, 2008, pp. 141-142).

In our view, the case management approaches and organisational arrangements could be more comprehensively modelled on three axes, illustrating basic criteria for making typological distinctions and strategic emphases formulated by proponents of differing case management types (see Figure 1). The first axis of our model, representing direct involvement of a case manager in care provision, runs between care limited to connecting clients to external services (as in the classical brokerage model) on one pole, and case managers doing many of the care tasks themselves (as, e.g., in the assertive community treatment), on the other pole. The second axis represents varying degrees of emphasis on autonomy and self-sufficiency of the client. Thus, on one pole of this axis, we could locate 
approaches stressing empowerment and autonomy (including some version of broker model and $\mathrm{ACT}$ ), while on the other we situate models giving priority to professional control. The third axis adds to and complicates the previous two, acknowledging economic considerations influencing designing and implementing case management models. On one pole of this axis, we see models stressing cost-effectiveness of the services, with case managers evaluating legitimacy of the client's needs against the legislation in force and then buying the services from the cheapest suppliers (as in some versions of the broker model), and on the opposite pole, case management approaches aiming at addressing the widest possible range of client's wishes and needs.

Whichever classification of case management or a way of modelling we are going to use for analytical and/or descriptive purposes, it is important to stress that in practice, autonomy and control, emphasis on costs and on needs, and efforts to limit direct care and getting directly involved are inextricably interwoven, creatively combined and variously enacted, depending on the case in question, on the structural conditions of care provision, and sometimes even on the personality of the individual case manager. Here, the distinction between autonomy and control is a good case in point. As ethnographic research of care has convincingly shown, the general emphasis on enhancing clients' autonomy does not prevent carers from taking over in certain situations, nor does it relieve them of the responsibility to judge repeatedly the ideal mix of control and letting go (see e.g. Pols 2004; Pols forthcoming). The situation is further complicated in the case of people living with dementia, whose cognitive abilities are severely limited in the later stages of the disease. Here, as in other areas of care, autonomy and taking over when necessary constitute different 'goods' of care, and the care process "implies a negotiation about how different goods might coexist in a given, specific, local practice" (Mol, Moser, \& Pols 2010, p. 13). "In practice," write Mol, Moser and Pols, "[...] seeking a compromise between different 'goods' does not necessarily depend on talk, but can also be a matter of practical tinkering, of attentive experimentation" (Mol, Moser, \& Pols 2010, p. 13). 
Figure 1: Modelling case management approaches

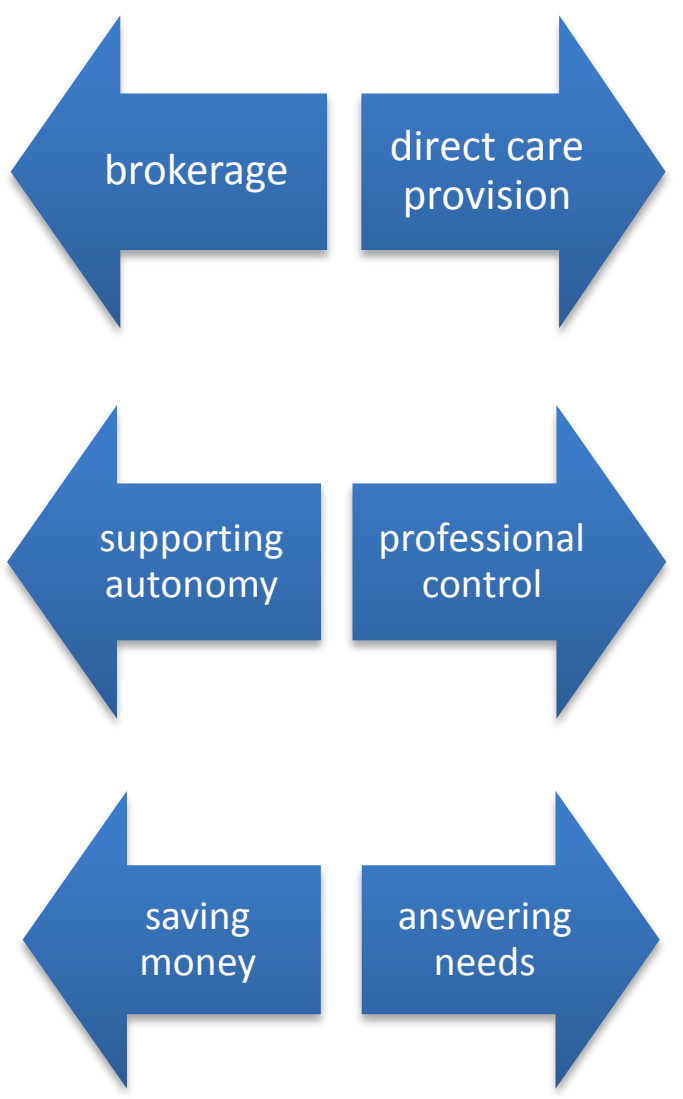

\section{Who can be a case manager?}

It is not clear which discipline should most efficiently carry out case management tasks. This may vary according to the systems of health and social care in different countries and regions, and even between users. For example, whilst close involvement of generalists in care co-ordination of the case management kind has been shown to lead to more costeffective care and better health, the structure of generalist practice does not easily lend itself to co-ordination of care (Stille et al., 2005). Acting as a case manager is both intellectually 
demanding and time-consuming. Co-ordination of the kind represented by case management involves regulation of participants to produce higher-order functioning; the immediate targets of case management are the health and social care system, which need to be made to function in a coherent and person-centred way. The second target is the disease process and its medical, social and psychological consequences for individuals (Stille et al., 2005). In addition, case managers can provide strategic leadership in the development of integrated services, and can contribute to the professional development of practitioners working on disease management at a lower risk level of the chronic disease management hierarchy (Boyd et al., 2005).

In the UK, policy documents suggest that whilst case managers can come from any health or social care professional background, nurses working in advanced practice roles are particularly well placed to be case managers for people with complex long term conditions (Department of Health, 2005). There are examples in the UK of nurses using case management techniques as part of their clinical practice tradition (Long et al., 2002; Evans, Drennan, \& Roberts, 2005), when working with social services (Weiner et al., 2003), as specialists working with people with multiple conditions (Boaden et al., 2005), and as clinical specialists for particular diseases or conditions (Forbes et al., 2003). Nursing in other European countries may not bring these traditions to a newly emerging interest in case management; but further investigations at national level are needed to clarify this.

A multiple case study of eight case management programmes for people with dementia in the Netherlands found that the background of the case managers varied both among and within the programmes (Minkman, Ligthart, \& Huijsman, 2009). Three of the surveyed programmes employed nurses as case managers, most of them specialized in elder care or mental health. The remaining teams consisted of nurses and social workers, with case managers receiving special training in some of the programmes. However, the diversity of the case managers' background in Dutch dementia care teams had to be subsequently 
abandoned due to changes in financing. Apart from meeting health insurance companies' requirements, the need to employ nurses as case managers is argued on the basis of required skills. Thus, a recent description of the Geriant model states that "[t]he clinical nature of Geriant's case management has its consequences for the professional qualifications that are required for it. While initially some of the case managers [...] had a background in social work, it was found that sufficient knowledge on dementia and nursing skills were required to perform the broad range of tasks inherent to the position" (Glimmerveen, \& Nies, 2015).

\section{Some European experience}

In some European countries, like Finland (Eloniemi-Sulkava et al., 2001; Eloniemi-Sulkava et al., 2009), the Netherlands (MacNeil Vroomen et al., 2012; Minkman, Ligthard, \& Huijsman, 2009; van Mierlo et al., 2014) and Sweden (Bodenheimer, Boestig, \& Henriks, 2007) case management is becoming well-established as 'normal care' for people with longterm conditions including dementia, although some studies still express uncertainties about its effectiveness for people with dementia (Jedenius et al., 2008). In other countries (like the UK, Germany or Spain), there is uncertainty about case management and mixed experiences of its implementation (Illife et al., 2014; Menn et al., 2013). In a third group of countries (Italy, Ireland, Czech Republic, Greece), the professional and health and social care systems may be interested in the idea of case management, without having experienced it.

After considering available evidence of the effectiveness of case management for people with dementia, we will concentrate more closely on one country from each of these three groups. 


\section{Evidence of effectiveness}

The research evidence about the value of case management for people with dementia, so far based mainly on quantitative research methods, is mixed. Pimouguet and colleagues (2010) published a systematic review of randomized controlled trials of case management for patients with dementia and their caregivers, and concluded that the evidence for the efficacy of case management with reference to cost and resource usage was not strong enough, and that further studies ought to consider who might benefit most from case management.

A systematic mixed methods review of case management for people with dementia, carried

out by Khanassov and colleagues (2014a; 2014b), analysed 31 quantitative and 12 qualitative studies. It concluded that case management in primary care needed to be a high intensity intervention with a small case-load, regular pro-active contact and close working between case managers and other practitioners, in order to produce positive outcomes.

The recent Cochrane Review of case management for dementia included 13 randomised controlled trials involving 9615 participants with dementia (Reilly et al., 2015). Those in the case management arms were significantly less likely to relocate to nursing homes in the 18 months following the start of case management. There were no statistically significant differences in hospital admissions at any point up to 18 months, nor any differences in mortality. Carer burden did decline and carer well-being improved at 6 months, but neither effect was prolonged, although carer depression showed a small but statistically significant reduction at 18 months. The case management group received more community services, but case management was associated with lower service costs at 12 months. There was considerable heterogeneity between interventions, outcomes measured, and the authors argue that further investigation of the effectiveness of different components of case management is required. 
Some well-conducted long-term studies from outside Europe have demonstrated how case management can delay relocation to a care home, with potentially important health and economic gains (Mittelman et al., 2006; Chien, \& Lee, 2008; Callahan et al., 2006).

\section{The Dutch experience}

In the Netherlands, the initial reason for introducing case management into the care of people with dementia was the increasing number of clients with cognitive problems in the caseload of social workers and specialized nurses, and the perceived need for more personcentred services for this group (Minkman, Ligthart, \& Huijsman, 2009). The approach taken has varied in different regions of the country, depending mostly on the local ways of organising dementia care networks. In the regions where care was provided by one major care organisation, a combined intensive case management/joint agency model was adopted, whereas in the areas with multiple care organisations in operation the linkage model had been given priority (van Mierlo et al., 2014). Since 2013, the need for further implementation of case management for people with dementia has been embodied in a Dementia Care Standard, describing case management as a standard approach to good care for people with dementia and their caregivers.

The results of the study conducted by Mierlo and her colleagues (Mierlo et al., 2014) have shown that the independence of the organisations using a combined intensive/joint agency model is one of the most important factors facilitating case management implementation. The impeding factors, found mostly in the linkage model, were mostly related to partners' collaboration inside the networks (van Mierlo et al., 2014). The authors' conclusion that case managers using the intensive case management model are more likely to provide quality care has been recently reasserted by a pragmatic trial study. This prospective, observational, controlled cohort study of 521 care dyads has found no meaningful effects on clinical outcomes. However, the intensive case management had a positive impact on caregivers' quality of life and the patient's number of needs compared with persons receiving 
case managed care through the linkage model and persons without access to case management (MacNeil Vroomen, et al., 2015). Intensive case management also appeared cost-effective compared with the linkage model and usual care (MacNeil Vrooman, et al, 2016)

The Geriant model is an example of Dutch integrated community-based care for people with dementia in which qualified case managers play an important role using an intensive case management/joint agency model. Case managers are the contact persons for the clients and their informal caregivers; their main task is coordination of services within the Geriant multidisciplinary team (social geriatricians, psychiatrists, clinical psychologists, dementia consultants, and specialised home care nurses) and with other providers in the region (GPs, hospitals, home care and welfare organisations). For more intensive treatment or observation, Geriant runs a 16-bed short-stay clinic (Goodwin et al., 2014). Inspired by the FACT model (flexible assertive community treatment; see Bak et al., 2007; Drukker et al., 2008; Firn et al., 2012) used in mental health care, Geriant's multidisciplinary teams flexibly adapt their services to clients' specific needs from the first presumption of dementia to the moment when they cannot live at home. The flexibility in the level of integration of services for each client and ability to accommodate uncertain and unpredictable developments in the clients' situation, including emergencies, are the big advantages of the model. The success of the Geriant model has been recognised in various evaluations and studies by its clients, their relatives and institutions. An important part of its success is the cooperation and relief it brings to general practitioners who often feel that they do not have the capacity to coordinate care for people with dementia (Glimmerveen, \& Nies, 2015).

Despite Geriant's success, acknowledged both by scientific studies and policy makers, recent developments suggest that in the near future case managers for people with dementia could become part of General Practitioners' multidisciplinary teams (an interview with Geriant's manager Paul-Jeroen Verkade). Primary care has been improving in terms of 
diagnoses of dementia and many GPs have been implementing a multidisciplinary approach to care for their patients. Such organization of care for people with dementia would support the clients in their own neighbourhoods. A successful model of the neighbourhood-based approach to the provision of services at the primary care level has been implemented by Buurtzorg Netherlands (Monsen, \& Blok, 2013). In 2015 Buurtzorg's nurses cared for over 70,000 patients, while some 50 per cent of their clients had some form of dementia (Royal College of Nursing, 2015). The model has gained international recognition for being entirely nurse-led. Self-governing community-based nursing teams deliver the full range of medical and support services to patients and families at rather low cost (Gray, Sarnak, \& Burgers, 2015). The holistic approach includes thorough assessment of patients' needs, mapping of networks of informal and formal care and promotion of self-care (Buurtzorg Nederland, 2011).

\section{The British experience}

In England when primary care based case management was introduced for (mostly) older people with long-term conditions (not just dementia) this generally failed to achieve its primary objective of reducing health service use (Goodman et al., 2010), even though it was appreciated by its recipients. Similarly, shifting experienced into case management roles may have diverted them from other activities, and was therefore resisted (lliffe et al., 2011). The widespread introduction of nurse case managers in England before the results of pilot studies were known generated interest (Morgan, 2005), but also provoked doubts about the viability of the role (Murphy, 2004; Cochrane, \& Fitzpatrick, 2005). This doubt was compounded by the subsequent evaluation of pilot studies which indicated that while there was some anecdotal evidence of patient level benefit, unplanned admissions to hospital were not reduced (Gravelle et al., 2007). The number of nurse case managers recruited in England never reached its target, and their case load was lower than expected. 
There are a number of explanations for the failure of nurse-led case management in England. Firstly, while the policy 'problem' selected was the high cost of unplanned hospital admissions, there was no consensus at service delivery level that a new group of nurses was the correct solution. Secondly, there was slow, uneven and limited establishment of nurse case manager posts across England. Finally, local implementation, in many areas driven by centrally monitored targets, was a pragmatic response to: a) local resistance to a contested role, b) the absence of any local 'demand' for such posts, c) limited financial resources, d) the presence of existing locally-developed service improvements in long term condition management, and e) the scarcity of suitably qualified and experienced nurses to fulfil these roles in some community settings (Goodman et al., 2010). In this policy and practice environment, it is not surprising that primary care based case management for older people, including those with dementia proved difficult to implement (Iliffe et al., 2014).

\section{The Czech experience}

In the Czech Republic continuity and coordination of health and social services are considered prerequisites of quality care for people living with dementia and their families. Nevertheless, problems with availability and fragmentation of services remain (Mátl, \& Mátlova, 2015). According to the study conducted by the Ministry of Labour and Social Affairs, informal as well as formal carers agree that support of a qualified care coordinator might be needed for the whole duration of the disease trajectory (MPSV, 2015). For many years, discussions concerning the needs of people with long-term care conditions include topics such as integrated care, community-based care and case management (Holmerová, Vaňková, \& Wija 2013). In the field of integrated services for older people, some success has been achieved in a few communities or small regions, although the specific role of care coordinator or manager was not officially established and integration of services depends on the personal relationships (rather than institutions) of formal and informal carers involved in care network. 
Czech experiences with case management as a method of care for people with serious longterm conditions come from fields other than dementia care (as care for people with mental health problems, drug users, endangered children etc.). Since the 1990s, NGOs Fokus and PDZ (Mental Health Care) provide community-based services for people with mental health problems in 10 towns and adjacent regions. Their method, developed to support clients living in private homes and in supported living, is based on the Dutch FACT model. Our research into the process of adaptation and development of this form of intensive case management inside the Czech health and social care systems indicates high adaptability of the model to the varying structural conditions. In the Czech version of FACT, case managers are mostly social workers and their work is partially state-funded from the social services budget (as 'social rehabilitation'). The involvement and/or recruitment of health care specialists (GPS, psychiatrists, nurses) remains problematic in terms of their capacity, funding and willingness to cooperate in a multidisciplinary team. But while the lack of multidisciplinarity brings certain limitations, some key technological features of the method (as the use of the 'FACT board'), as well as at least some of the general aims (such as emphasis on cooperation and empowerment), remain functional. More than 20 years of successful operation (Hejzlar, 2010) indicate that the structural and economic limitations might be overcome by connecting the translated pattern to different resources (e.g. in the Czech context, to European funding).

Preliminary findings from the authors' research in a community based clinic for older people and people with dementia, offering outpatient, short-stay clinic and home services in the capital, show that involvement of geriatricians, psychologists, specialised home care nurses and social workers (similarly as in the Geriant model) is highly beneficial to people with dementia and their families. However, due to structural and economic factors, the clinic does not provide long-term support of the case management type through the whole disease trajectory. Without funding for case managers, the cooperation with most of the clients remains discontinuous, and continual long-term intensive care is provided only under specific circumstances (e.g. if people are not being served by different geriatricians and live 
in the vicinity) and based on clients' ability to remain in contact. Despite being appreciated by the clients, family carers and the general public, this community based clinic remains a unique project.

\section{Translation of the case management method}

Many studies aiming at evaluating present experiences of case management for people with dementia have found evidence in favour of the method unclear and contested, partly because of the multiplicity of case management forms in use (Low, Yap, \& Brodaty, 2011). Despite the mixed results of scientific, largely quantitative studies, case management for people with dementia has spread across Europe - after travelling from differing fields and sites - with some countries adopting it as a standard approach to elder care (as in the Netherlands), others experimenting with its use (as in Great Britain), and still others exploring available evidence for and against it and pondering its introduction into existing care networks (as in the Czech Republic).

Meanwhile, as we have shown above, the definitions and forms of the case management method vary considerably across sites, as well as the research methods and outcomes used for its evaluation. Because of this, the widely used diffusion model (see, e.g., Berwick, 2003) seems to be rather problematic as a tool for understanding the processes of adoption and translation of the case management methods in different conditions. This model assumes a linear process, through which an object (in our case the method of case management), is accepted, or rejected thanks to its intrinsic qualities, by a society, which constitutes a more or less receptive environment. An important component of constructing such a model is separating analysis of the object per se (and its properties), and analysis of the environment in which it spreads (Akrich, Callon, \& Latour, 2002a). But, as has been demonstrated by a series of a case studies (Akrich, 1992; Callon, 1986; Kidder, 1982; Molet, Sataury, \& van 
Gigh, 1985), what we observe in the process of adopting innovation is rather an emergence of a new object, associated with those who handle it with a hybrid cluster of connections (often with an unclear direction of the trajectory) linking a number of different actors (human and non-human). To describe such a situation, Alkrich, Callon and Latour propose the model of interessement. According to this model, the object and the social environment in which it is implemented shape and transform each other in mutual interaction. To adopt an innovation then largely means to adapt to the new environment (Akrich, Callon, \& Latour, 2002b, pp. 208-209). "The model of diffusion restricts the work of elaboration to the limited circle of the designers responsible for the project," write Akrich, Callon and Latour, while "the model of interessement underlines the collective dimension of innovation. In the former, the majority of actors are passive; in the latter, it is active. In the former, the innovation is either taken up or left; in the latter, adoption is synonymous with adaptation" (Akrich, Callon, \& Latour, 2002a, p. 205).

The career of the case management method through the processes of interessement is influenced by many human and non-human actors, including service providers and users, policy makers, health insurance companies, existing health care systems and their infrastructures, values informing the care provision, etc., as well as scientists and their research methods. And while some of the actors might value standardisation, unification and generalisation, others might prefer heterogeneity and adaptability.

Some of us have argued before that "[f]uture research should be built around a common agreed definition of types of case management [...]" (Koch et al., 2012). This statement reflects the conventional idea that trials of complex interventions (like case management) require as much clarity as possible and that efforts should be made to ensure fidelity of the case management practice to the commonly agreed, universalised definition. From the point of view of actors who build their understanding through generalising locally specific experiences on the basis of unified descriptions and evaluation criteria, the multiplicity and 
heterogeneity of case management models and of the ways of their implementation might be viewed as an obstacle to diffusion of case management into new health and social care environments. On the other hand, the generalizing of the many case management models in use might prove difficult or untenable, and the emphasis on unification and standardization itself might complicate the process of co-constitution (Akrich, 1993; Mol, 2010) of the method (case management) and its environment (the social and health care system with all their cultural, political, historical and other complexities).

Building on the notions of interessement and co-constitution, we could offer a model of translation which allows for conceptualising both the efforts to stabilise key factors of the technology in question, and the need for flexibility and adaptability. On the basis of their research on the Zimbabwe bush pump, De Laet and Mol (De Laet, \& Mol 2000) describe the process of successful dissemination of a 'fluid technology' or 'fluid object'. The concept of fluidity, we believe, can be useful for considering possibilities for the translation and expansion of the case management method. According to De Laet and Mol, the fluid object has no unchanging core, but instead is constituted by components that are necessary for its functionality. Its boundaries are vague and unclear - they are established differently in each of the communities where the technology is being used. Thus, rather than insisting on any solid form, it is better to learn from the ways the technology was developed, adapted and rebuilt in different places. Being sensitive to the varying needs and complex circumstances and leaving sufficient space for the community itself to participate in the adoption and maintenance of the technology are basic prerequisites for its successful dissemination. Apart from that, fluid technology is flexible in using alternative components and works even without some of its parts (that can be replaced from local sources), opening a space for tinkering by the community. In the process of co-constitution, the community itself is transformed and newly constituted in relation to the technology, and as the translated object is not associated with any particular inventor, authorship is the result of collective action and development over time. 


\section{Conclusion}

The research for this article is a part of wider efforts aimed at evaluating European experiences with case management for people with dementia and their carers and exploring its viability in and translation into health and social care networks of a country where case management to this specific client group has not been provided (the Czech Republic). In this article, we presented some ideas on case management's functioning, effectiveness and modes of translation, hoping to provide a point of departure for future research and debates about possibilities for its introduction into new health and social care environments.

Our review of relevant literature and experiences with implementation in three European countries shows case management for people with dementia as a highly variable and hybrid object, recognizable in many different forms in varying environments. In literature and in practice, very different ways of caring could be encountered under the heading of case management, which compromises efforts to make statements about the worth of case management in general. From the point of view of evidence based medicine, the calls for unification of definitions and standardization of research methods might seem unproblematic and straightforward. However, they might be problematized in encounters with the method resisting unification and standardisation by constantly changing its form and content. Thus we might ask what kind of evidence and what level of generalisation is appropriate to facilitate better understanding of case management.

Firstly, as RCT evidence for case management for people living with dementia is not conclusive, and long-term impact and cost-effectiveness - the major concern of most of the studies - are hard to prove across the broad spectrum of case management interventions, we propose introducing new outcome measures, such as quality of life, impact on 
relationships, care load etc., including outcome measures which are hard or impossible to asses through RCTs. Apart from the new outcome measures, a different methodology - e.g. qualitative, ethnographically oriented research - might be needed to ask not only what and how much, but also how and why. How and why questions are, in our opinion, especially suitable if the object of inquiry (e.g. case management for people living with dementia) is unstable and fluid.

Secondly, we suggest that generalizations should always be limited to relevant fields of application. While the need for general statements as "case management is/is not an effective method of dementia care" might be strongly felt in the fields of bio-medicine and nursing science, it might be more reasonable and practical to ask how specific versions of case management come into being/disappear, prosper/malfunction, etc., given specific circumstances.

If on methodological grounds a case for more nuanced, case-oriented modelling and research could be made on the basis of available studies, from the point of view of translational science based on the model of interessement both standardisation and calls for respecting multiplicity and flexibility must be assessed as important modes of ordering (Law, 1994, pp. 20-22, 73-93) influencing the success and spread of a technology in question. Further research into the ways by which the case management methods travel across times and sites might show how different modes of ordering case management (with research methods playing an important role) interact and collide, and if and how they obstruct efforts at translation. From this perspective, the wide range of existing models of case management, difficulties in finding a single definition of the method and of its properties, as well as varying characteristics of the environment where it is intended to be implemented, not only lose their intrinsically problematic nature, but open up a space for future research, as well as for negotiation and tuning of a case management model to the different circumstances and needs. 


\section{Declaration of Conflicting Interests}

The author(s) declared no potential conflicts of interest with respect to the research, authorship, and/or publication of this article. 


\section{References}

Akrich, M. (1992). The De-Scription of Technical Objects. In: W.E. Bijker \& J. Law (Eds.), Shaping Technology/Building Society: Studies in Sociotechnical Change (pp. 205-224). Cambridge: MIT Press.

Akrich, M. (1993). Essay of Technosociology: A Gasogene in Costa Rica. In: P. Lemonnier (Ed.), Technological Choices. Transformation in Material Cultures since the Neolithic (pp. 289-337). London: Routledge.

Akrich, M., Callon, M., \& Latour, B. (2002a). The key to success in innovation part I: The art of interessement. International Journal of Innovation Management, 6(2), 187-206.

Akrich, M., Callon, M., \& Latour, M. (2002b). The key to success in innovation part II: The art of choosing good spokespersons. International Journal of Innovation Management, 6(2), 207-225.

Backhouse, A., Dickens, C., Richards, D., \& McCabe, R. (2015). Key components in models of community-based interventions coordinating care in dementia: a mixed studies systematic review protocol. Systematic Reviews, 4, 156.

Bak, M., van Os, J., Delespaul, P., de Bie, A., a Campo, J., Poddighe, G., \& Drukker, M. (2007). An observational, "real life" trial of the introduction of assertive community treatment in a geographically defined area using clinical rather than service use outcome criteria. Social Psychiatry Psychiatric Epidemiology, 42(2), 125-30.

Batsch, N. L., \& Mittelman, M. S. (2012). World Alzheimer Report 2012: Overcoming the stigma of dementia. Available from:

https://www.alz.org/documents custom/world report 2012 final.pdf Accessed 1/2/16.

Beardshow, V., \& Towell, D. (1990). Assessment and Case Management: Implications for the Implementation of Caring for People (Briefing paper No. 10). London: King's Fund Institute. 
Berwick, D. (2003). Disseminating innovations in health care. Journal of American Medical Association, 289(15), 1969-1975.

Boaden, R., Dusheiko, M., Gravelle, H., Parker, S., Pickard, S., Roland, M., Sheaff, R., \& Sargent, P. (2005). Evercare evaluation interim report: implications for supporting people with long term conditions. Manchester: NPCRDC, University of Manchester.

Bodenheimer, T., Boestig, M., \& Henriks, G. (2007). Making system-wide improvements in health care: lessons from Jönköping County, Sweden. Quality Management in Health Care,16(1), 10-15.

Boyd, C. M., Darer, J., Boult, C., Fried, L. P., Boult, L., \& Wu, A. W. (2005). Clinical practice guidelines and quality of care for older patients with multiple co-morbid diseases. Journal of the American Medical Association, 294(6), 716-724.

Buurtzorg Nederland (2011). A new perspective on elder care in the Netherlands. Available from: http://omahasystem.org/AARPTheJournal Summer2011 deBlok.pdf. Accessed 18/09/16.

Callahan, C., Boustani, M., Unverzagt F. V., Austrom, M. G., Damush, T. M., Perkins, A. J., Fultz, B. A., Hui, S. L., Counsell, S. R., \& Hendrie, H. C. (2006). Effectiveness of collaborative care for older adults with Alzheimer Disease in primary care: a randomized controlled trial. Journal of the American Medical Association, 295(18), 2148-2157.

Callon, M. (1986). The sociology of an actor-network: The case of the electric vehicle. In: M. Callon, J. Law, \& A. Rip, Mapping the Dynamics of Science and Technology (pp. 19-34). Basingstoke: MacMillan.

Case Management Society UK. (2010). What is Case Management. Available from: https://www.cmsuk.org/case-management/what-is-case-management. Accessed 23/6/2016. Chien, W.T., \& Lee, Y.M. (2008). A disease management program for families of persons in Hong Kong with dementia. Psychiatric Services, 59(4), 433-436. 
Cochrane, D., \& Fitzpatrick, S. (2005). Case management. Matrons: are they really on the case? The Health Service Journal, 115(5985), 32-33.

Connolly, A., Campbell, S., Gaehl, E., lliffe, S., Drake, R., Morris, J., Martin, H., \& Purandare, N. (2013). Under-provision of medical care for vascular diseases for people with dementia in primary care: a cross-sectional review. British Journal of General Practice, 63(607), e88-e96.

Cooper, C., Lodwick, R., Walters, K., Raine, R., Manthorpe, J., lliffe, S., \& Petersen, I. (2016). Observational cohort study: Deprivation and access to anti-dementia drugs in the UK. Age \& Ageing, 45(1), 148-154.

De Laet, M., \& Mol, A. (2000). The Zimbabwe Bush Pump: Mechanics of a Fluid Technology. Social Studies of Science, 30, 225-263.

Department of Health (2004). Improving chronic disease management. London: DoH. Department of Health. (2005). Supporting People with Long Term Conditions: An NHS and social care model to support local innovation and integration. London: DoH.

Dill, A. E. P. (2006). Case Management. In: D. Mitchell, \& S. Snyder, (Eds.), Encyclopedia of Disability (pp. 228-231). Thousand Oaks/London/New Delhi: Sage Publications.

Drennan, V., Goodman, C. (2004). Nurse-led case management for older people with longterm conditions. British Journal of Community Nursing, 9 (12), 527-33.

Drukker, M., Maarschalkerweerd, M., Bak, M., Driessen, G., à Campo, J., de Bie, A., Poddighe, G., van Os, J., \& Delespaul, P. (2008). A real-life observational study of the effectiveness of FACT in a Dutch mental health region. BMC Psychiatry, 8(93).

Dustin, D. (2007). The MacDonaldization of Social Work. Aldershot, Burlington: Ashgate. Eggers, T., Norberg, A., \& Ekman, S. L. (2005). Counteracting fragmentation in the care of people with moderate and severe dementia. Clinical Nursing Research, 14(4), 343-369. 
Eloniemi-Sulkava, U., Notkola, I. L., Hentinen, M., Kivelä, S. L., Sivenius, J., \& Sulkava, R. (2001). Effects of supporting community-living demented patients and their caregivers. A randomized trial. Journal of the American Geriatrics Society, 49(10), 1282-1287.

Eloniemi-Sulkava, U., Saarenheimo, M., Laakkonen, M. L., Savikko, N., Kautiainen, H., Tilvis, R.S., \& Pitkälä, K.H. (2009). Family care as collaboration: effectiveness of a multicomponent support program for elderly couples with dementia. Randomized controlled intervention study. Journal of the American Geriatrics Society; 57(12), 2200-2208.

Evans, C., Drennan, V., \& Roberts, J. (2005). Practice nurses and older people: a case management approach to care. Journal of Advanced Nursing, 51(4), 343-352.

Firn, M., Hindhaugh, K., Hubbeling, D., Davies, G., Jones, B., \& White, S. J. (2012). A dismantling study of assertive outreach services: comparing activity and outcomes following replacement with the FACT model. Social Psychiatry Psychiatric Epidemiology, 48(6), 9971003.

Forbes, A., While, A., Dyson, L., Grocott, T., \& Griffiths, P. (2003). Impact of clinical nurse specialists in multiple sclerosis: synthesis of the evidence. Journal of Advanced Nursing, 42(5), 442-462.

Furnish, S. (2002). Services for people with dementia and their carers. In: M. Warner, S. Furnish, M. Longley, \& B. Lawlor (Eds.), Alzheimer's Disease: policy and practice across Europe (pp. 89-134). Oxford: Radcliffe Medical Press.

Glimmerveen, L., \& Nies, H. (2015). Integrated community-based dementia care: The Geriant model. International Journal of Integrated Care, 15.

Goodman, C., Drennan, V., Davies, S., Masey, H., Gage, H., Scott, C., Manthorpe, J., Brearley, S., \& Iliffe, S. (2010). Nurses as case managers in primary care: the contribution to chronic disease management. SDO Report. National Institute of Health Research, Southampton. 
Goodwin, N., Dixon, A., Anderson, G., \& Wodchis, W. (2014). Providing integrated care for older people with complex needs. Lessons from seven international case studies. London: The King's Fund. Available from:

http://www.kingsfund.org.uk/publications/providingintegrated-care-older-people-complexneeds. Accessed 25/6/16.

Gravelle, H., Dusheiko, M., Sheaff, R., Sargent, P., Boaden, R., Pickard, S., Parker, S., \& Roland, M. (2007). Impact of case management (Evercare) on frail elderly patients: controlled before and after analysis of quantitative outcome data. BMJ, 334 (7583), 31. Gray, A. (2012). Public service users face a fragmented landscape of providers which makes integrated care more difficult to effect. Available from:

http://blogs.Ise.ac.uk/politicsandpolicy/archives/23959. Accessed 1/2/16.

Gray, B. H., Sarnak, D. O., \& Burgers, J. S. (2015). Home Care by Self-Governing Nursing Teams: The Netherlands' Buurtzorg Model. The Commonwealth Fund. Available from: http://www.commonwealthfund.org/publications/case-studies/2015/may/home-care-nursingteams-netherlands. Accessed 13/9/16.

Hejzlar, P. (Ed.). (2010). Na cestě ke komunitní psychiatrii... Sborník k 15 letům občanského sdružení Péče o duševní zdraví [Towards Community Psychiatry... Anthology to the 15th Anniversary of non-governmental organization Mental Health Care]. Pardubice: PDZ a Theo. Holmerová, I., Vaňková, H., \& Wija, P. (2013). Opportunities and Challenges for Integrated Provision of Long-term Care Services in the Czech Republic. In: Széman Zsuzsa (Ed.), Challenges of Ageing Societies in the Visegrad Countries: Hungary, Czech Republic, Poland, Slovakia. Budapest: Hungarian Charity Service of the Order of Malta.

Iliffe, S., Drennan, V., Manthorpe, J., Gage, H., Davies, S., Massey, H., Scott, C., Brearley, S., \& Goodman, C. (2011). Nurse case management and General Practice: implications for practice-based commissioning. British Journal of Clinical Pharmacology, 61(591), 658-665. 
Iliffe, S., Waugh, A., Poole, M., Bamford, C., Brittain, K., Chew-Graham, C., Fox, C., Katona, C., Livingston, G., Manthorpe, J., Steen, N., Stephens, B., Hogan, V., \& Robinson, L. for the CAREDEM research team. (2014). The effectiveness of collaborative care for people with memory problems in primary care: results of the CAREDEM case management modelling and feasibility study. Health Technology Assessment, 18(52).

Jedenius, E., Wimo, A., Strömqvist, J., \& Andreasen, N. (2008). A Swedish programme for dementia diagnostics in primary health care. Scandinavian Journal of Primary Health Care, 26(4), 235-250,

Jones, S., Howard, L., \& Thornicroft, G. (2008). 'Diagnostic overshadowing': worse physical health care for people with mental illness. Acta Psychiatrica Scandinavica, 118, 169-171.

Kanter, J. (1989). Clinical case management: Definition, principles, components. Hospital and Community Psychiatry, 40 (4), 361-368.

Khanassov, V., Vedel, I., \& Pluye, P. (2014a). Case management for dementia in primary health care: a systematic mixed studies review based on the diffusion of innovation model. Clinical Interventions in Aging, 9, 915-928.

Khanassov. V., Vedel, I., \& Pluye, P. (2014b). Barriers to implementation of case management for patients with dementia: a systematic mixed studies review. Annals of Family Medicine, 12(5), 456-465.

Kidder, T. (1982). The Soul of a New Machine. London: Allen Lane.

Koch, T., \& Iliffe, S. (2010). Rapid appraisal of barriers to the diagnosis and management of dementia in primary care: a systematic review. BMC Family Practice, 1(52).

Koch, T., lliffe, S., Manthorpe, J., Stephens, B., Fox, C., Robinson, L., Livingston, G., Coulton, S., Knapp, M., Chew-Graham, C., \& Katona, C. (2012). The potential of case management for people with dementia: a commentary. International Journal of Geriatric Psychiatry, 27(12), 1305-1314. 
Law, J., 1994. Organizing Modernity. Oxford, Cambridge: Blackwell Publishers.

Leichsenring, K., Billings, J., \& Nies, J. H. (Eds.) (2013). Long-Term Care in

Europe: Improving Policy and Practice. Houndmills, New York: Palgrave Macmillan.

Long, A. F., Kneafsey, R., Ryan, J., \& Berry, J. (2002). The role of the nurse in the multi professional rehabilitation team. Journal of Advanced Nursing, 37(1), 70-78.

Low, L. F., Yap, M., \& Brodaty, H. (2011). A systematic review of different models of home and community care services for older persons. BMC Health Services Research, 11, 93.

MacNeil Vroomen, J., Van Mierlo, L. D., van de Ven, P. M., Bosmans, J. E., van den Dungen, P., Meiland, F. J. M., Dröes, R., Moll van Charante, E. P., van der Horst, H. E., de Rooij, S. E., \& van Hout, H. P. J. (2012). Comparing Dutch Case management care models for people with dementia and their caregivers: The design of the COMPAS study. BMC Health Services Research, 12(132).

MacNeil Vroomen, J., Bosmans, J. E., van de Ven, P. M., Joling, K. J., van Mierlo, L. D., Meiland, F. J. M., Moll van Charante, E. P., van Hout, H. P. J., \& de Rooij, S. E. (2015). Community-Dwelling Patients with Dementia and Their Informal Caregivers with and without Case Management: 2-Year Outcomes of a Pragmatic Trial. Journal of the American Medical Directors Association, 16(9), 800.1e-8.

MacNeil Vroomen, J., Bosmans, J. E., Eekhout, I., Joling, K. J., van Mierlo, L. D., Meiland, F. J. M., van Hout, H. P. J., \& de Rooij, S. E. (2016). The cost-effectiveness of two forms of case management compared to a control group for persons with dementia and their informal caregivers from a societal perspective. PLoS one, 11(9), e0160908.

Mátl, O., \& Mátlová, M. (2015). Zpráva o stavu demence 2015. Jaký názor má veřejnost a co prezentují média. [Dementia Report 2015. Public opinion and media presentation]. Praha: ČALS.

McLean, A. (2007). Dementia Care as a Moral Enterprise: A Call for a Return to the Sanctity of Lived Time. Alzheimer's Care Today, 8(4), 360-372. 
Menn, P., Holle, R., Kunz, S., Donath, C., Lauterberg, J., Leidl, R., Marx, P., Mehlig, H., Ruckdäschel, S., Vollmar, H. C., Wunder, S., \& Grässel. (2013). Dementia care in the general practice setting: a cluster randomized trial on the effectiveness and cost impact of three management strategies. Value in Health, 15(6), 851-859.

van Mierlo, L. D., Meiland, F. J. M., van Hout, H. P. J., \& Dröes, R.-M. (2014). Towards personalized integrated dementia care: a qualitative study into the implementation of different models of case management. BMC Geriatrics, 14(84).

Minkman, M. M. N., Ligthard, S. A., \& Huijsman, R. (2009). Integrated dementia care in The Netherlands: a multiple case study of case management programmes. Health and Social Care in the Community, 17(5), 485-494.

Mittelman, M., Haley, W., Clay, O., \& Roth D. (2006) Improving caregiver well-being delays nursing home placement of patients with Alzheimer Disease. Neurology, 67(9), 1592-1599. Mol, A. (2010). Actor-Network Theory: Sensitive Terms and Enduring Tensions. Kölner Zeitschrift für Soziologie und Sozialpsychologie Sonderhefte, 50, 253-269.

Mol, A., Moser, I., \& Pols, J. (Eds.). (2010). Care in Practice: On Tinkering in Clinics, Homes and Farms. Bielefeld: Transcript Verlag.

Molet, H., Sataury, J. P., \& van Gigh. J. P. (1985). Robot en Rodage: Les Enseignements d'une Perirobotique Retive. Paris: CGS, Ecole Nationale Superieure des Mines de Paris. Monsen, K., de Blok, J. (2013). Buurtzorg Nederland. American Journal of Nursing, 113(8), $55-59$.

Morgan, M. (2005). New opportunities for district nursing: chronic disease and matrons. British Journal of Community Nursing, 10(1), 6-7.

MPSV. (2015). Studie o možnostech a významu zavedení koordinátora podpory pro pečující osoby a osoby odkázané na pomoc druhých. [Study on possibility and significance of introduction of care coordinator for carers and care dependent persons] Available from: 
https://koopolis.cz/sekce/knihovna/499-vystupy-projektu-podpora-neformalnich-pecovatelu. Accessed 18/09/16.

Murphy, E. (2004). Case management and community matrons for long term conditions. BMJ, 329 (7477), 1251-1252.

Penrod, J., Yu, F., Kolanowski, A., Fick, D. M., Loeb, S, J., \& Hupcey, E. (2007). Reframing Person-Centered Nursing Care for Persons with Dementia. Research and Theory for Nursing Practice, 21(1), 57-72.

Pimouguet, C., Lavaud, T., Dartigues, J., \& Helmer, C. (2010). Dementia case management effectiveness on health care costs and resource utilization: a systematic review of randomized controlled trials. Journal of Nutrition, Health \& Aging, 14(8), 669-676.

Pols, J. (2004). Enforcing Patient Rights or Improving Care? The Interferences of Two Modes of Doing Good in Mental Health Care. PhD dissertation, University of Twente.

Pols, J. (forthcoming). Limits of Autonomy.

Royal College of Nursing. (2015). The Buurtzorg Nederland (home care provider) model. Available from: https://www2.rcn.org.uk/ data/assets/pdf file/0003/618231/02.15-TheBuurtzorg-Nederland-home-care-provider-model.-Observations-for-the-UK.pdf. Accessed 18/09/16.

Reilly, S., Miranda-Castillo, C., Malouf, R., Hoe, J., Toot, S., Challis, D., \& Orrell, M. (2015). Case management approaches to home support for people with dementia. Cochrane Database of Systematic Reviews (Online), 1(1), CD008345.

Stille, C. J., Jerant, A., Bell, D., Meltzer, D., \& Elmore, J. G. (2005). Coordinating care across diseases, settings and clinicians: a key role for generalists in practice. Annals of Internal Medicine, 142(8), 700-708.

Walsh, J. (2002). Clinical case management. In: A. Roberts, \& G. Greene (Eds.), Social workers' desk reference (pp. 472-476). New York: Oxford University Press. 
Walsh, J., \& Holton, V. (2008). Case management. In: W. Rowe \& L. A. Rapp-Paglicci (Eds.), Comprehensive Handbook of Social Work and Social Welfare, Social Work Practice, (Vol. 3, pp. 139-160). Hoboken: John Wiley \& Sons, Inc.

Warner, M., \& Furnish, S. (2002). Towards coherent policy and practice in Alzheimer's disease across the EU. In: M. Warner, S. Furnish, M. Longley, \& B. Lawlor (Eds.), Alzheimer's Disease: policy and practice across Europe (pp. 175-192). Oxford: Radcliffe Medical Press.

Weiner, K., Hughes, J., Challis, D., \& Pedersen, I. (2003). Integrating Health and Social Care at the Micro-Level: Health Care Professionals as Care Managers for Older People. Social Policy \& Administration, 37(5), 498-515. 